UHERO

THE ECONOMIC RESEARCH ORGANIZATION AT THE UNIVERSITY OF HAWAIII

\section{ELECTRIC UTILITY REGULATION UNDER ENHANCED RENEWABLE ENERGY INTEGRATION AND DISTRIBUTED GENERATION}

BY

NORI TARUI

Working Paper No. 2017-2

March 6, 2017 
Electric utility regulation under enhanced renewable energy integration and distributed generation

March 2017

\begin{abstract}
Nori Tarui*
Department of Economics, University of Hawaii at Manoa

University of Hawaii Economic Research Organization (UHERO)
\end{abstract}

\begin{abstract}
The economic environment for electric utilities is changing in the United States given increased penetration of distributed generation and limited rooms for sales growth. This paper reviews the recent development of relevant policies in the United States and their economic impacts. This review indicates both challenges and opportunities in improving the policies to enhance distributed generation, and in finding the directions in which electric utility regulation should be reformed.
\end{abstract}

Keywords: renewable energy, renewable portfolio standard, clean energy tax credit, net energy metering, utility regulation

JEL classification: H23, H24, L51, Q48

\footnotetext{
*2424 Maile Way, Saunders 542, Honolulu, HI 96822, USA. Email: nori@hawaii.edu, Phone: $+1-808-956-8427$.
} 


\section{Introduction}

Since the late 2000s, there has been an increased attention by policy makers and academics on policies to enhance the integration of renewable energy and distributed generation in the electricity markets over the United States. ${ }^{1}$ In the Journal of Environmental Economics and Management, for example, 7 (11) out of 456 articles in 2008 to 2015 have "renewable energy" ("energy efficiency") as a keyword while no article carried the same keyword between 1990 and 2007. Together with the increased presence of renewables and distributed generation, researchers have raised concerns about their implications to the electric utilities' economic performance under various forms of current regulation, and the possible future changes in the utility regulation.

The concern is expressed with a term such as "utility death spiral" (e.g., Borenstein and Bushnell 2015) and an argument for exploring a "new business model" for electric utilities (e.g., Goldman et al. 2013). With distributed generation and improved energy efficiency, the utilities' sales of electricity are expected to grow slower or decrease. Many distributed generators rely on intermittent sources (such as solar power); a large-scale integration of such sources would require investment to improve the electric grid for stable electricity supply. With the prospect of lower sales, the utilities would increase the electric rates, thereby encouraging further distributed generation. "Utility death spiral" captures such possible downward spiral, and is discussed in the media, government reports, and academic papers. For example, Greentech Media reports that "as grid maintenance costs go up and the capital cost of renewable energy moves down, more customers will be

${ }^{1}$ Distributed generation refers to electricity generation at end users' sites as opposed to centralized generation at traditional large-scale power plants. 
encouraged to leave the grid. In turn, that pushes grid costs even higher for the remainder of customers, who then have even more incentive to become self-sufficient. Meanwhile, utilities are stuck with a growing pile of stranded assets" (Greentech Media, March 4, 2014). MIT Energy Initiative (2011) states “[r]educed consumption threatens the ability of a distribution utility to recover its predominantly fixed costs" (p.184).

To understand these concerns, this paper reviews some of the trends in the U.S. electricity markets and relevant policies to enhance renewables integration and distributed generation. It then studies a form of regulatory provisions aiming at alleviating the potentially negative impacts of such trends and policies on utilities' economic performance, and concludes by discussing research opportunities on utility regulatory reforms.

One of the most significant changes in the U.S. electricity generation is the increased role of natural gas, together with a decline in the presence of coal, in the nation's fuel mix (Figure 1). ${ }^{2}$ Coal, which accounted for about $50 \%$ of total generation over several decades, experienced a decline in its share at the end of the 2000 s (to less than $40 \%$ in 2014). Coalpowered electricity generation decreased not only in share but also in scale. Though the recession in 2009 is partly responsible for the downward trend in coal-powered generation, it is unlikely the only reason as natural gas exhibits a contrasting trend. While the share of natural gas in electricity generation hovered around $20 \%$ until the early 2000 s, it now stays at around $30 \%$. In fact, the shares of coal and natural gas have gotten closer to each other than ever before. As explained below, the U.S. shale gas development and the

2 The description of U.S. electricity generation comes from various issues of U.S. Energy Information Administration's Annual Energy Review and Short-term Energy Outlook. 
contemporaneous changes in environmental regulation appear to explain these contrast trends in the usage of coal and natural gas.

The federal environmental regulation on electricity generation increased its stringency under the Obama Administration. With Mercury and Air Toxics Standards for Power Plants (announced in December 2011), the federal government imposed national emission standards for power plant air toxics (that are not the criteria pollutants, regulated under the U.S. Clean Air Act) for the first time. In addition, U.S. Environmental Protection Agency announced "Clean Power Plan" in June 2014, which seeks to cut the carbon dioxide (CO2) emissions from power plants 30\% from 2005 levels by $2030 .^{3}$ This constitutes the firstever national CO2 emissions standards on power plants. The Clean Power Plan is expected to reduce the share of coal-powered electricity from about 33\% (under the baseline scenario without the Plan) to about $27 \%$ by 2030 (U.S. EPA 2015).

What explains these trends in the U.S. energy mix and tighter environmental regulation on power plants? A crucial factor among others is the shale gas development. With the invention and the increased use of hydraulic fracturing technology, large oil resources, which are locked in shale deposits, were made commercially accessible. Introduction of such unconventional oil, while directly contributing to the increased role of natural gas, arguably made it politically less challenging for the federal government to place larger regulatory pressures on the use of coal. With natural gas as a viable alterative, the cost of limiting the use of coal-the most pollution intensive among fossil fuels-would be lower.

${ }^{3}$ In the final version announced in August 2015, this target is strengthened to $32 \%$. 
The increased focus on renewable energy and distributed generation could be understood in the policy environment discussed above. Until the Clean Power Plan was adopted, no federal regulation directly controlled greenhouse gas (GHG) emissions. As in many other countries, the U.S. has counted on increasing the use of renewable energy (that are much less GHG intensive than fossil fuel), via quantity targets and subsidies, instead of limiting or taxing its GHG emissions directly. This article reviews some of the major policy instruments that enhance the use of renewable energy and distributed generation as well as the challenges associated with the economic impacts of such policies (Section 2). ${ }^{4}$

Though utility-scale wind power commands the majority of the increase in renewables generation, distributed generation has also increased its presence (and its contribution is expected to increase) as discussed below. The accompanying improvement in energy efficiency and renewables integration is, on the other hand, making it more difficult than ever for electric utilities to increase their sales and profits. Section 3 addresses the tradeoffs in electric utility regulation in terms of encouraging efficient utility operation and inducing cost-effective distributed generation. These tradeoffs lead to the following question: what regulation aligns utilities' incentives with the regulator's policy goals that enhance distributed generation, energy-efficiency improvement? As a case study, Section 3 studies a policy provision adopted in many U.S. states in this context (revenue decoupling for electric utilities) and describes the challenges that such policies pose in meeting the tradeoffs described above. Section 4 concludes the discussion.

${ }^{4}$ See, for example, Moselle et al. (2010) and Schmalensee (2012) for a comprehensive review of the utility-scale renewables development in the United States. 


\section{Policies to enhance electricity from renewable sources and distributed generation}

This section reviews three policy instruments on renewable energy use and distributed generation: a policy to increase the overall use of renewable energy (renewable portfolio standards), a policy to support distributed generation (income tax credit for solar photovoltaic (PV) installation), and a policy that enables end users with distributed generation units to sell electricity back to the grid (net energy metering).

\subsection{Renewable Portfolio Standards}

A renewable portfolio standard (RPS) specifies a minimum amount (usually specified in percentage) of electricity generated or sold to come from renewable sources. In the United States, 29 states (along with Washington, DC and three U.S. territories) have RPS in place as of June 2015 while there is none at the federal level (www.dsireusa.org). Ten of those RPS policies were enacted between 1996 and 2000 while the majority of the states with RPS (17) enacted RPS between 2004 and 2009. Many of them have been revised with more stringent standards subsequently (Barbose 2016). Together, the RPS policies cover more than half of total U.S. electricity sales. Except for a few exceptions, almost all state-level RPS targets have been achieved as of 2013 (Barbose 2016). 
RPS compliance is usually measured on an annual basis. The way RPS is implemented differs across states—not only in terms of the target level (e.g., 33\% by 2020 in California, 5,880MW capacity by 2015 in Texas, and 100\% by 2045 in Hawaii) but also in terms of the design. In states with organized wholesale markets ${ }^{5}$ (such as New England and California), either electric utilities or distribution companies are responsible for meeting RPS targets. ${ }^{6}$ In such markets, the regulated entities can meet RPS via trading of renewable energy certificates (RECs). In other states, a single firm (a vertically integrated utility) owns all generation, transmission network, and distribution network for a geographic area. Such utilities are typically subject to cost-of-service regulation, where state public utility commissions regulate the prices of electricity services so that each utility's revenue covers the total costs as well as an allowed rate of return on its capital assets. Most states with RPS have REC trading. ${ }^{7}$ Schmalensee (2012) notes that, depending on how electricity supply is governed, RPS has different impacts on the incidence of the costs of introducing renewable energy. On one hand, under cost-of service (or rate-of-return) regulation, ratepayers must bear all of the incremental costs of shifting to renewables that are not borne by taxpayers (Schmalensee 2012, p.49). This is because the utilities' conventional, fossil fuel units whose

\footnotetext{
${ }^{5}$ An "organized wholesale market" refers to a market for wholesale electricity, typically with a large number of electricity generators, conducted by a third-party independent operator of the transmission system (RTO, regional transmission organization, or ISO, independent system operator).

${ }^{6}$ Distribution of electricity refers to the delivery of electricity from the transmission system to end users through a network of power lines, and has natural monopoly characteristic even as electricity generation and retail sectors are deregulated.

${ }^{7}$ Exceptions include Hawaii and Vermont. A small number of utilities might explain the case of Hawaii with no RPS trading (where vertically integrated utilities own most of the generating capacity while each island has an isolated grid) though that does not explain Vermont's case, where electric utilities own little generating capacity and rely on contracts with independent generators and power from neighboring states and Canada (EIA State Profile and Energy Estimates).
} 
generation is replaced by renewables are subject to guaranteed rates of return. On the other hand, in those states with competitive wholesale markets, the conventional generators would experience lower profits as renewables substitute their generation (Schmalensee 2012, p.49). This argument may also imply that how RPS encourages utilityscale renewables generations, as opposed to distributed generation, may also depend on the structure of the electric industry.

Under RPS with RECs, renewable generators can sell their power at the market price of RECs while the regulated utilities purchase them to meet RPS. While states differ in the flexibility of RECs trading, many of them allow trading across states if they belong to the same electricity markets (under the same independent system operator or regional transmission organization). ${ }^{8}$ This provision thus helps reduce the overall RPS compliance costs of the states allowing such inter-state trading. For example, Massachusetts, which has relatively less renewable sources, met $82 \%$ of its RECS in 2013 by importing renewablesbased electricity from other states such as New York and Maine (Massachusetts RPS Annual Compliance Report, 2013). The fact that many states meet their RPS via REC trading with other states implies further potential gains from trade if a federal, nation-wide RPS is to be implemented.

\footnotetext{
${ }^{8}$ Independent system operators and regional transmission organizations refer to thirdparty independent operators of the electric transmission system. Some states regulate geographic eligibility of RECs. States such as Colorado and Illinois had provisions to prioritize in-state renewables generation (Leon 2012, pp.35-36).
} 
Distributed generation does not have a strong presence in the U.S. total generation capacity. ${ }^{9}$ However, it accounts for a growing portion of RPS compliance in several states. In Hawaii, about 32\% of its compliance in 2014 is due to distributed PV (Hawaiian Electric Company Renewable Portfolio Compliance Report). In California, the total wholesale renewable capacity in 2014 was $18,800 \mathrm{MW}$ while online renewable distributed generation totaled 5,200MW. ${ }^{10}$ California has set a goal on renewable distributed generation capacity of $12,000 \mathrm{MW}$ by 2020 . Some states (including California), however, do not count residential PV towards RPS (Barbose 2016).

\subsection{Subsidies for distributed generation}

\section{Federal Personal Tax Credit}

Federal income tax credit has been available for residential Solar PV and most other renewable energy systems since 2006.11 Tax credit reduces taxable income for taxpayers with renewable energy systems, thereby reducing their tax liabilities. The tax credit amount is $30 \%$ of the expenditure on the generation system with no maximum limit on solar-electric systems, solar water heaters, wind turbines, and geothermal heat pumps placed in service after $2008 . .^{12}$ The federal tax credit program, which was set to expire on December 31, 2016, was extended in December 2015 until 2021 (NC Clean Energy Technology Center and Meister Consultants Group 2016). This extension may lessen

\footnotetext{
${ }^{9}$ Residential net-metered capacity is about 3.3GW while the total U.S. generation capacity is 1,055GW as of 2014 (EIA Form EIA-826 and EIA Annual Energy Review). ${ }^{10}$ State of California Energy Commission (2014) Summary of Renewable Energy Installations: Current and Planned in California (Revised December 31, 2014).

${ }^{11}$ http://www.energystar.gov/about/federal_tax_credits.

12 There is a maximum limit on fuel cells ( $\$ 500$ per $0.5 \mathrm{~kW}$ ).
} 
concerns that discontinuing federal tax credit would have slowed down solar diffusion in the United States.

\section{Personal Tax Credit at the state level}

As of June 2015, 17 states offer additional state-level tax credit to the residential customers with solar PV. ${ }^{13}$ Some states specify tax credit in terms of the percentage of the cost (e.g., 35\% in Hawaii, 25\% in Arizona) while others specify tax credit per kWh generated (e.g., $\$ 0.015 / \mathrm{kWh}$ in Iowa) or per capacity size (e.g., \$3/W DC in Kentucky). State-level tax incentives are decreasing or set to expire in a few years (NC Clean Energy Technology Center and Meister Consultants Group 2015).

The tax credit for clean energy may impose a sizable burden on states' budgets. Hawaii's 2012 renewable technology tax credit amounted to about $\$ 179$ Million-more than $48 \%$ of the total tax credits in the same tax year (Department of Taxation, State of Hawaii 2014). ${ }^{14}$ Coffman et al. (2016) estimate that, under the current tax credit level, a total of 1,115MW could be installed on owner-occupied single-family homes, at a total cost of $\$ 1.4$ billion. Given the size of the state budget, this is a significant amount of expenditure.

\footnotetext{
13 The states include Arizona (25\%), Hawaii (35\%), Idaho (40\% first year, 20\% per year for next three years), Iowa ( $\$ 0.015 / \mathrm{kWh}$ or $\$ 0.01 / \mathrm{kWh}$ for 10 years after facility begins producing energy), Kentucky (\$3/W DC), Louisiana, Maryland, Massachusetts (15\%), Montana, Nebraska, New Mexico, New York, North Carolina, South Carolina, Oregon, Rhode Island, and Utah. Information about the state-level policies related to renewable energy is archived at http://www.dsireusa.org/.

${ }^{14}$ The majority of the Renewable Energy Technologies Income Tax Credit was applied for solar systems by individuals.
} 


\subsection{Net energy metering}

Net energy metering (NEM) intends to promote renewable electricity generation in a decentralized way, thereby reducing utilities' generation that is mostly based on conventional energy sources (fossil fuel, hydroelectric, or nuclear power). Net metering allows customers to connect their renewable generators (e.g. solar panels on their rooftop) to the utility grid. Customers can export surplus electricity into the grid, and receive credits (typically) at full retail value, which can be used to offset electricity purchases over a 12month period.

The average PV penetration among residential customers is less than $1 \%$ at the national level. The state of Hawaii is leading with about $12 \%$ penetration..$^{15}$ Though the penetration level is still low, its growth rate is significant: while the number of NEM resident customers was less than 6,000 in 2003, it exceeded 719,000 as of May 2015 (indicating the growth rate of about $50 \%$ per year). ${ }^{16}$

The fact that households can sell excess electricity generated from rooftop panels at the retail price (instead of the wholesale price of generation) implies that NEM tends to work as an implicit subsidy for distributed generation (to the extent that the credit payment for electricity sent from distributed units to the grid exceeds the concurrent marginal cost of electricity generation). However, whether it is indeed a subsidy depends on how the

\footnotetext{
15 Hawaiian Electric Companies News Release, "Hawaiian Electric Companies continue to move ahead with rooftop PV," dated February 25, 2015.

16 U.S. Energy Information Administration Form EIA-826.
} 
electric rate is structured (e.g., whether the rate differs depend on time of use, and how solar output profile is correlated with the load profile).

\subsection{Economic impacts of supporting renewable energy}

Impacts on greenhouse gas emissions

In contrast to policies that raise the price of greenhouse gas emissions via emissions tax or emissions trading, subsidizing renewable energy (via subsidies, RPS or feed-in tariffs) is considered a second-best policy for climate-change mitigation (as detailed below). To the extent that learning by doing (and the associated external economies in reducing the costs of renewable energy generation) exists, subsidizing the use of renewables is justified. However, such infant-industry arguments tend to apply only at the initial stage of the technology deployment. For example, van Benthem et al. (2008)'s simulation indicates that the optimal incentives for PV installation in California would decline at 13\% per year-thus justifying the projected reduction in the incentives that California Solar Initiative (CSI) provides. The current declining trend of federal and state tax credit, along with downgrading of net metering, also coincide with the trend.

What does the literature say about the cost-effectiveness of renewables subsidies as a policy to reduce GHG emissions? Overall, studies find that "policies that create incentives for fossil-fueled generators to reduce emissions intensity, and for consumers to conserve energy, perform better than those that rely on incentives for renewable energy producers alone" (Fischer and Newell 2008). Murray et al. (2014) conclude that, despite tax revenue 
losses of $\$ 10$ billion per year in 2010 , the federal tax provisions (not just the personal income tax credit but including all production and investment tax credit) have a very small impact on GHG emissions because the amount of renewable energy increased via the tax provisions is limited in scale. Renewables subsidies, without fossil taxes, need to be substantially high to achieve the same climate goal as the taxes would accomplish (Newell 2008, Palmer et al. 2011). Palmer and Burtraw (2005) estimate that RPS, if adopted nationally in the United States, will raise electricity prices. As discussed below, increased electricity prices, among other factors, lead to concerns about distributional impacts of supporting renewables.

\section{Distributional impacts}

Besides cost-effectiveness, another concern about RPS is its distributional impacts. For example, Rausch and Mowers' (2014) CGE analysis finds that RPS tends to have a regressive impact on households because (i) energy constitutes a larger share in household expenditure for low-income households; and (ii) households with high capital income shares (which tend to have high income) benefit from returns on new investments in clean generating capacity.

Addressing the distributional impacts of clean-energy income tax credits, Borenstein and Davis's (2015) empirical study based on U.S. tax return data delivers a similar message. They find that federal income tax credits for weatherizing homes, installing solar panels, purchasing hybrid and electric vehicles, and other clean energy investments have gone 
mostly to high-income households. According to their estimates, the top income quintile has received about $60 \%$ of all credits (and about $90 \%$ of all electric-vehicle credits).

Some researchers are concerned about the distributional effects of net metering through its impacts on electricity bills including those who do not have NEM units (i.e. those without PV ${ }^{17}$. In general, the fixed-rate portion of electricity bills is not enough to cover the whole fixed costs of providing electricity services. Instead, the variable, volumetric charges cover not only the variable costs (e.g. fuel costs) but also a portion of the fixed costs. As more customers adopt PV panels and utilize NEM, the utility's revenue will shrink. However, NEM customers would typically stay connected to the grid because solar power is intermittent and they receive electricity from the grid when their PV generation is lower than their consumption. In order to cover the costs of the whole electricity services, the utility would then need to increase the electricity rates (which is possible even in the short run under revenue decoupling, as discussed in the next section).

\section{$\underline{\text { Impacts on electric power systems }}$}

There is also a concern about the impacts of integrating renewable and distributed generations in a large scale on the electric power systems. The impacts could emerge in a number of ways. First, integration of intermittent energy sources, whose generation may vary unpredictably, poses a challenge on the grid operation as electricity supplied and consumed must be balanced with each other constantly (given that energy storage

17 The discussion here is based on Borenstein, S. "Solar Initiative has a dark side," www.mercurynews.com, posted on August 20, 2004, and "Hawaii leads the nation in electricity prices," "Loss of tax credits might dim solar industry," Star Advertiser, February 1 and 5, 2012. 
technology is still limited for large-scale deployment). The impacts on system stability are not perhaps very visible in the mainland (possibly except for California, which leads the nation in terms of the installed PV capacity). However, in Hawaii, which leads the nation in terms of PV penetration, the impacts have been felt, causing a discussion about adjusting the policies to encourage renewables and distributed generation described above. For example, Borenstein (2015a) notes that "[PV systems] can actually destabilize distribution circuits when they pump too much power back into the grid. In Hawaii, where $12 \%$ of houses now have rooftop solar, that's already a serious concern."

The second concern (related to the first) applies to the impacts of PV penetration on the load profile. This is due to the fact that the solar generation profile and the load (consumption) profile are different. ${ }^{18}$ As PV penetrates further, the net load tends to get lower during the daytime when the sunshine is strong. In the mean time, the evening peak demand might increase as the population increases or the (regional) economy expands. Thus the daytime generation from power plants may have to be controlled (to address "over-generation risk") while the system operator needs to increase generation rapidly toward the peak time due to "ramping demands."19 These concerns indicate that demand response efforts that encourage energy conservation and load shifting would be increasingly valuable, and indeed critical, as renewables are integrated.

\footnotetext{
${ }^{18}$ Baker et al. (2013) provides a comprehensive discussion about the pricing of solar output given the relative profiles of load and PV output. ${ }^{19}$ See, for example, Fowlie (2014) for a description of ramping demands due to PV integration and other challenges associated with renewable integration. A source of the "duck curve," which describes how the load profile could change over time as renewable integration expands, is available at California ISO (2013).
} 
As these issues gather attention, the distributional impacts of renewables integration policies, how to alleviate the system instability, and how to pay for stabilizing the grid are all emerging as important policy issues. For example, reforming NEM has become a major energy policy issue in Hawaii. The issue involves whether net metering provides implicit subsidies for ratepayers with solar panels, whether it should be lowered on efficiency and equity grounds, and whether NEM customers should face higher fixed charges to pay for benefits from grid connection (whose management involves significant fixed costs). With such concerns in the background, Hawaii's Public Utilities Commission discontinued NEM in $2015 .{ }^{20}$ Under the new arrangement, surpluses or deficits of net electricity consumption are no longer carried over across months; and the price paid to electricity from distributed solar systems is reduced from the retail rate to a lower fixed rate. As distributed generation is enhanced across the U.S. states, the optimal design of NEM or its alternatives will become an important research and policy agenda (Coffman et al. 2015).

\section{Utility regulation for energy efficiency and renewables transition}

\subsection{Changing economic environment for electric utilities}

Figure 1 indicated what changed significantly in the U.S. electricity generation over the last decade-in particular, the shares of coal and natural gas in the fuel mix. The figure also indicates what has not changed much over the last decade, i.e., the total generation quantity. U.S. EIA predicts that the trend of slowing growth in electricity demand will

${ }^{20}$ Decision and Order No. 33258, Public Utilities Commission, State of Hawaii, October 12, 2015. 
continue over the next 20 years (with about $1 \%$ growth per year). ${ }^{21}$ The slowing growth in the demand for electricity, the accompanying improvement in energy efficiency, and substitution away from fossil fuel to renewable sources all indicate that electric utilities' sales may continue to decline in the near future. This trend poses the following question: how are the utilities best regulated in the environment of declining sales?

Why is this question important? As distributed generation expands, the utilities' sales will decrease. As technology associated with distributed generation and energy storage advances, some ratepayers may choose to opt out of the grid ("grid defection"). Such grid defection is not likely to occur in a significant scale given the current state of technology (Borenstein 2015a). Even though grid defection might become a viable option as relevant technologies (distributed generation and electricity storage) advance, the grid and utilities are expected to remain indispensable in electric power systems. In a traditional environment, marginal cost pricing, with fixed fees covering the fixed cost of electricity services, might achieve the efficient allocation of electricity services though many highlight the incentive issues associated with how the fixed charge is set and the presence of asymmetric information between the regulated natural monopoly and the regulator (Joskow 2008). Given the prevalent practice of above-marginal-cost pricing, utilities' sales declines lead to lower profits for the utilities. With distributed generation, an added complication is the two-way flow of electricity between the grid and the end users. Integrating intermittent distributed generation would thus require investments in the grid to maintain stable electric power systems.

${ }^{21}$ U.S. Energy Information Administration, Annual Energy Outlook 2013, Market Trends, April 15, 2013 
How the costs of supporting renewables will be contained and distributed is likely a challenging question for the future electric power systems. As we see below, the case of revenue decoupling provides an informative example of the challenges associated with the future of electric utility regulation.

\subsection{A case study: revenue decoupling}

Revenue decoupling is a utility regulation provision that helps utilities maintain their revenue when their sales drop. Because of the natural monopoly characteristics, the electric utilities (investor-owned utilities) have been under federal and state regulation for a long time (since the early 1900s, Greer 2012, Chapter 3). The traditional public utility regulation determines an allowed rate of return on the utility's capital base and fixes a set of electric rates (prices) accordingly. The rates are fixed unless the utility or the regulator initiates a formal rate case to update them. ${ }^{22}$ Under such traditional rate-of-return regulation, electric utilities have an incentive to increase sales (i.e. sell as much electricity as possible) in order to increase profits. This is because, as discussed above, the regulator (a public utilities commission) sets the electricity rates above the marginal costs so that the utility can recover the total costs of its services, allowing it to earn a "fair" rate of return on its capital base. Thus the larger the sales, the larger the profit that the utility could earn. Such an incentive for increasing sales is in conflict with the regulators' interest in improving energy efficiency. With increased interests in energy efficiency improvement,

${ }^{22}$ Joskow (1974) documents in detail the traditional regulatory process of public utilities. 
many U.S. states have adopted regulatory reforms so that utilities do not have an incentive to increase sales. "Revenue decoupling" is one such reform adopted in several states.

Revenue decoupling eliminates the relationship between revenues and sales volume. Under such a compensation scheme, revenues are "decoupled" from sales and are instead allowed to adjust—when the actual sales deviate from what was projected due to, say, increased energy conservation in the residential sector-so that utilities receive fair compensation regardless of fluctuations in sales (see Graniere 1994 and Eto et al. 1997 for an early review of revenue decoupling regulation). As of 2014, 17 states have electric utility decoupling in place..$^{23}$

Few studies have analyzed the effectiveness of revenue decoupling. ${ }^{24}$ Using U.S. utilities' data from 1981 to 1996, Knittel (2002) finds that revenue decoupling is not statistically associated with greater efficiency levels of power plants. Arimura et al. (2012) find that decoupling is not statistically associated with smaller electricity demand by using data from U.S. utilities in 1992-2006. Tarui and Brucal (2014) study the effect of revenue decoupling on electricity rates, renewable energy penetration, the regulated utility's profits, and the welfare. As long as the demand for electricity is inelastic, the electric rate must increase for the revenue to stay constant (as the sales drop). On one hand, higher

\footnotetext{
${ }^{23}$ Natural Resources Defense Council, http://www.nrdc.org/energy/decoupling/, accessed on August 3, 2015.

${ }^{24}$ See, for example, Brennan (2011), Chu and Sappington (2013), and American Council for an Energy Efficient Economy, http://aceee.org/sector/state-policy/toolkit/utilityprograms/lost-margin-recovery (retrieved February 28, 2017) on theoretical concerns about revenue decoupling.
} 
electric rates could increase the households' incentive to install solar panels to reduce the electricity purchase from the utility, and thus will contribute to further solar energy penetration. On the other hand, the increased rates would have a negative impact on those households without solar panels. The overall welfare impact turns out be worse with revenue decoupling than without. Just as clean energy income tax credit has a regressive aspect, revenue decoupling also has negative distributional consequences on low-income households because of increases in electricity prices. In addition, as distributed generation expands, at some point revenue decoupling becomes unsustainable: the utility will not be able to keep the same revenue with any price change.

The primary justification of revenue decoupling is that it removes the disincentives for utilities to promote end-users' energy efficiency. However, another rationale for revenue decoupling is that it avoids the utility from running losses when its sales drop (due to increased distributed generation of electricity in particular). Some concerns have been raised regarding potential negative effects of revenue decoupling, including (i) decoupled utilities may lose incentives for improving their own operational efficiency; (ii) decoupling, with the implied stable revenues, may shift the risks in energy prices and quantities from the utility to the end users, and (iii) whether utilities' may enjoy excess profits due to decoupling. ${ }^{25}$

25 Such concerns have been made by Kondo (2008) on Hawaii's decoupling, Dismukes (2010) on Indiana's, and by a consumer advocate on Nevada's case (Las Vegas Sun "NV Energy stands to gain from late add in bill," May 17, 2009). 
Figure 2 indicates that the magnitude of the rate increase in Hawaii due to revenue decoupling. The trend during the first two years of its implementation (until mid 2013) is consistent with the finding based on a U.S. national study (Morgan 2012): the impact of decoupling on the electric rates was small. ${ }^{26}$ In the case of Hawaii, however, the decoupling adjustment has exceeded $6 \%$ of the rate since November 2014. The figure demonstrates the steady increase in revenue decoupling adjustments while the electric rates fluctuated without a clear trend. ${ }^{27}$ The rate increases due to decoupling adjustments in the future are likely to be larger as the state is expected to expand the scale of distributed generation further. Coffman et al. (2016) indicate that a total of 1,115MW could be installed on owneroccupied single-family homes. With large-scale adoption of solar panels, it is possible that more significant rate increases become inevitable. Then the State will face a decision as to whether decreasing (or stabilizing) the electricity rates or supporting renewable energy should be prioritized. In fact, in April 2015 Hawaii's Public Utilities Commission (PUC) issued an order to restructure decoupling (in particular the Revenue Adjustment Mechanism, RAM) in order to limit the amount of unapproved capital project expenditures that can automatically be incorporated into effective rates through RAM without timely prior regulatory review. ${ }^{28}$ This is due to the concerns that the decline in the utility's sales

\footnotetext{
${ }^{26}$ Morgan (2012) documents that, of 1,244 decoupling adjustments made to the rates over the U.S. in $2005-2012,64 \%$ are within plus or minus $2 \%$ of the retail rates. However, $20 \%$ of the adjustments involved rate increases exceeding $2 \%$.

27 The electric rate fluctuation is largely due to changes in the price of fuel oil and the associated fuel cost adjustments.

${ }^{28}$ In 2010, Hawaii's Public Utilities Commission approved a decoupling mechanism, which entails: (1) a sales decoupling component, or Revenue Balancing Account, which is intended to break the link between the Hawaiian Electric Companies' sales and their total electric revenues; and (2) a Revenue Adjustment Mechanism, which is intended to compensate the Hawaiian Electric Companies for increases in utility costs and infrastructure investment.
} 
has been accompanied with increases in electricity rates (and that the regulated utility increased its requests for capital expenditure approvals). ${ }^{29}$

What we observe in Hawaii now is likely to occur in the rest of the United States and in Asia as renewable energy and distributed generation are integrated further. A more comprehensive assessment of revenue decoupling will require empirical studies that assess the mechanism's actual performance under renewables penetrations over the U.S. states including Hawaii. Though it has not received as much attention in the mainland U.S. as in Hawaii, the issue related to revenue decoupling will become pertinent as the scale of distributed and renewable generation increases across the states.

\section{Discussion}

This paper reviewed some of the major policy instruments to encourage distributed electricity generation and studies about the associated economic and distributional impacts. Renewable portfolio standard, clean energy income tax credit, and net energy metering all contributed to renewable expansion. In the future, these policies need reforms for alleviating the associated efficiency and distributional issues.

Even as generation (and retail) is deregulated, local distribution services will remain to be regulated because of large fixed costs associated with electricity provision services. This will hold true even if distributed generation expands. The common rate structures, where a

\footnotetext{
${ }^{29}$ Hawaii Public Utilities Commission Docket No. 2013-141 ("Instituting an Investigation to Reexamine the Existing Decoupling Mechanisms for Hawaiian Electric Company, Inc., Hawaii Electric Light Company, Inc., and Maui Electric Company, Limited").
} 
large portion of the fixed costs is recovered through variable (volumetric) charges, will not support efficient introduction of distributed generation. Nor will it allow the utilities to recover costs unless a provision such as revenue decoupling is in place. As the previous section describes, revenue decoupling has its own drawbacks in terms of both efficiency and equity.

These considerations pose both challenges and opportunities associated with energy policy reforms. In particular, how can electric utilities be best regulated for their incentives to be aligned with regulators' objectives including further energy efficiency improvement and further renewables integration? What might be a viable alternative for revenue decoupling? What rate structure reforms would enhance efficient deployment of renewables-distributed or at the utility scale—while addressing fairness concerns? How should net energy metering be redesigned? They will remain to be important research questions.

Comparing the cases of regulatory challenges in the United States and Asian countries could generate useful implications about the ongoing and future energy policy reforms in these regions. For example, IEA (2012) notes that South Korea has been leading among Asian countries in its effort to enhance renewable energy technology development while the electricity market reforms have been slow. Reforming electricity markets, with renewable energy having a stronger presence, is pursued in several other Asian countries including the Philippines (Fabella 2016). Japan's electricity market also provides an example of regulatory challenges as described in this paper. Given concerns about reliance 
on nuclear power after the Fukushima accident in 2011, Japan is increasing its reliance on oil- and natural gas fired power generation on one hand and has been accelerating its policies to encourage renewable energy adoption (including feed-in tariffs in 2012) on the other. The feed-in tariffs in Japan, initially set at high levels compared to those in other countries, encouraged solar diffusions. However, in 2014 Kyushu Electric Power decided cut access to its grid for renewable energy suppliers because of concerns about network limitations (Reuters September 25, 2014). With deregulation in the retail sector and unbundling of transmission and distribution, the above incidence indicates research needs on finding policies to aligns electric utilities' incentive with the regulator's policy targets that involve enhanced energy efficiency and distributed generation.

\section{Acknowledgment}

The author acknowledges financial support from the Center for Global Partnership, Japan Foundation (PI: Toshi Arimura). The author thanks Syed Khan and Arlan Brucal for their research assistance.

\section{References}

Arimura, T. H., Li, S., Newell, R. G., \& Palmer, K. (2012). Cost-Effectiveness of Electricity Energy Efficiency Programs. Energy Journal, 33(2), pp.63-98.

Baker, E., Fowlie, M., Lemoine, D., \& Reynolds, S. S. (2013). The Economics of Solar Electricity. Annual Review of Resource Economics, 5(1), 387-426.

Barbose, G. (2016). U.S. Renewables Portfolio Standards: 2016 Annual Status Report. Lawrence Berkeley National Laboratory. 
Borenstein, S. (2015). Is the Future of Electricity Generation Really Distributed [Web log post]? Retrieved from https://energyathaas.wordpress.com/2015/05/04/is-thefuture-of-electricity-generation-really-distributed/.

Borenstein, S., Bushnell, J. (2015) The US Electricity Industry After 20 Years of Restructuring. Annual Review of Economics, 7: 437-463.

Borenstein, S., Davis, L. (2015). The Distributional Effects of US Clean Energy Tax Credits. NBER Working Paper No. 21437.

Brennan, T. J. (2010). Decoupling in electric utilities. Journal of Regulatory Economics, 38(1), pp.49-69.

Brennan, T. (2011). Energy efficiency policy: Surveying the puzzles. Resources for the Future Discussion Paper, (pp.11-27).

California Independent System Operator (2013). Fast Facts: What the duck curve tells us about managing a green grid. Available at https://www.caiso.com/Documents/FlexibleResourcesHelpRenewables_FastFacts.pd $\underline{\mathrm{f}}$

Chu, L. Y., and Sappington, D. E. (2013). Motivating energy suppliers to promote energy conservation. Journal of Regulatory Economics, 43(3), 229-247.

Coffman, M., Wee, S., Bonham, C., and Salim, G. (2016). "A Policy Analysis of Hawaii's Solar Tax Credit Incentive," Renewable Energy, 85: 2036-1043.

Coffman, M., Fripp, M., Roberts, M.J., Tarui, N. (2015) Efficient Design of Net Metering Agreements in Hawaii and Beyond. University of Hawaii Economic Research Organization 
Department of Taxation, Tax Credits Claimed by Hawaii Taxpayers Tax Year 2012. State of Hawaii, 2014. Available at http://files.hawaii.gov/tax/stats/stats/credits/2012credit.pdf.

Dismukes, D. E. (2010) “Direct Testimony of Dr. David E. Dismukes - Public’s Exhibit No.2 on Behalf of the Indiana Office of Utility Consumer Counselor," State of Indiana Utility Regulatory Commission Cause No. 43839.

US Energy Information Administration (EIA) State Energy Data System.

US Environmental Protection Agency (EPA). State CO2 Emissions from Fossil Fuel Combustion, 1990-2011.

Eto, J., Stoft, S., \& Belden, T. (1997). The theory and practice of decoupling utility revenues from sales. Utilities Policy, 6(1), 43-55.

Fabella, R.V. (2016) The Market Testing of Power Supply Agreements: Rationale and Design Evolution in the Philippines. Energy Policy and Development Program Working Paper 2016-03, University of the Philippines.

Fischer, C., \& Newell, R. G. (2008). Environmental and technology policies for climate mitigation. Journal of environmental economics and management, 55(2), pp.142-162.

Fowlie, M. Renewable integration challenges create demand response opportunities [Web log post]. Retrieved from https://energyathaas.wordpress.com/2014/09/02/renewable-integrationchallenges-create-demand-response-opportunities/.

Goldman, C., Satchwell, A., Cappers, P., \& Hoffman, I. M. (2013). Utility Business Models in a Low Load Growth/High DG Future: Gazing Into the Crystal Ball. Committee on 
Regional Electric Power Cooperation \& State-Provincial Steering Committee, Lawrence Berkeley National Laboratory.

Graniere, R. J. (1994). Decoupling and public utility regulation. The National Regulatory Research Institute, The Ohio State University, Research Report 94-14.

Greer, M. (2012). Electricity Marginal Cost Pricing. Elsevier. International Energy Agency (2012) Energy Policies of IEA Countries: The Republic of Korea 2012 Review.

Joskow, P. L. (1974). Inflation and environmental concern: Structural change in the process of public utility price regulation. Journal of Law and Economics, 17, 291.

Joskow, P. L. (2008). Incentive regulation and its application to electricity networks. Review of Network Economics, 7(4) 1-14.

Knittel, C. R. (2002). Alternative regulatory methods and firm efficiency: stochastic frontier evidence from the US electricity industry. Review of Economics and Statistics, 84(3), pp.530-540.

Kondo, L. (2008). "Dissenting Opinion of Leslie H. Kondo, Commissioner," State of Hawaii Public Utilities Commission Docket No. 2008-0274.

Leon, W. (2012) Designing a Right RPS. Clean Energy States Alliance.

MIT Energy Initiative (2011). The future of the electric grid. Massachusetts Institute of Technology.

Morgan, P. (2012) A Decade of Decoupling for US Energy Utilities: Rate Impacts, Designs, and Observations. Graceful Systems LLC.

Moselle, Boas, Jorge Padilla and Richard Schmalensee, eds. (2010). Harnessing Renewable Energy in Electric Power Systems RFF Press/Earthscan. 
Murray, B. C., Cropper, M. L., de la Chesnaye, F. C., Reilly, J. M. (2014). How Effective Are US Renewable Energy Subsidies in Cutting Greenhouse Gases?. American Economic Review, 104(5), 569-574.

NC Clean Energy Technology Center and Meister Consultants Group (2015) The Fifty States of Solar. Available online at http://nccleantech.ncsu.edu/wp-content/uploads/50States-of-Solar-Issue2-Q2-2015-FINAL3.pdf.

Palmer, K., and Burtraw, D. (2005). Cost-effectiveness of renewable electricity policies. Energy Economics, 27(6), pp.873-894.

Palmer, K., Paul, A., Woerman, M., Steinberg, D.C., 2011. Federal policies for renewable electricity: impacts and interactions. Energy Policy 39, 3975-3991.

Rausch, S., and Mowers, M. (2014). Distributional and efficiency impacts of clean and renewable energy standards for electricity. Resource and Energy Economics, 36(2), 556-585.

Schmalensee, R. (2012). Evaluating policies to increase electricity generation from renewable energy. Review of Environmental Economics and Policy, 6(1), 45-64.

Tarui, N., and Brucal, A. (2014). Distributional Impacts of Revenue Decoupling for Electric Utilities, Paper presented at the Fifth World Congress of Environmental and Resource Economists, Istanbul, Turkey. http://www.webmeets.com/WCERE/2014/prog/viewpaper.asp?pid=1781

United States Environmental Protection Agency (2015) Regulatory Impact Analysis for the Clean Power Plan Final Rule. EPA-452/R-15-003.

Van Benthem, A., Gillingham, K., and Sweeney, J. (2008). Learning-by-doing and the optimal solar policy in California. The Energy Journal, 131-151. 


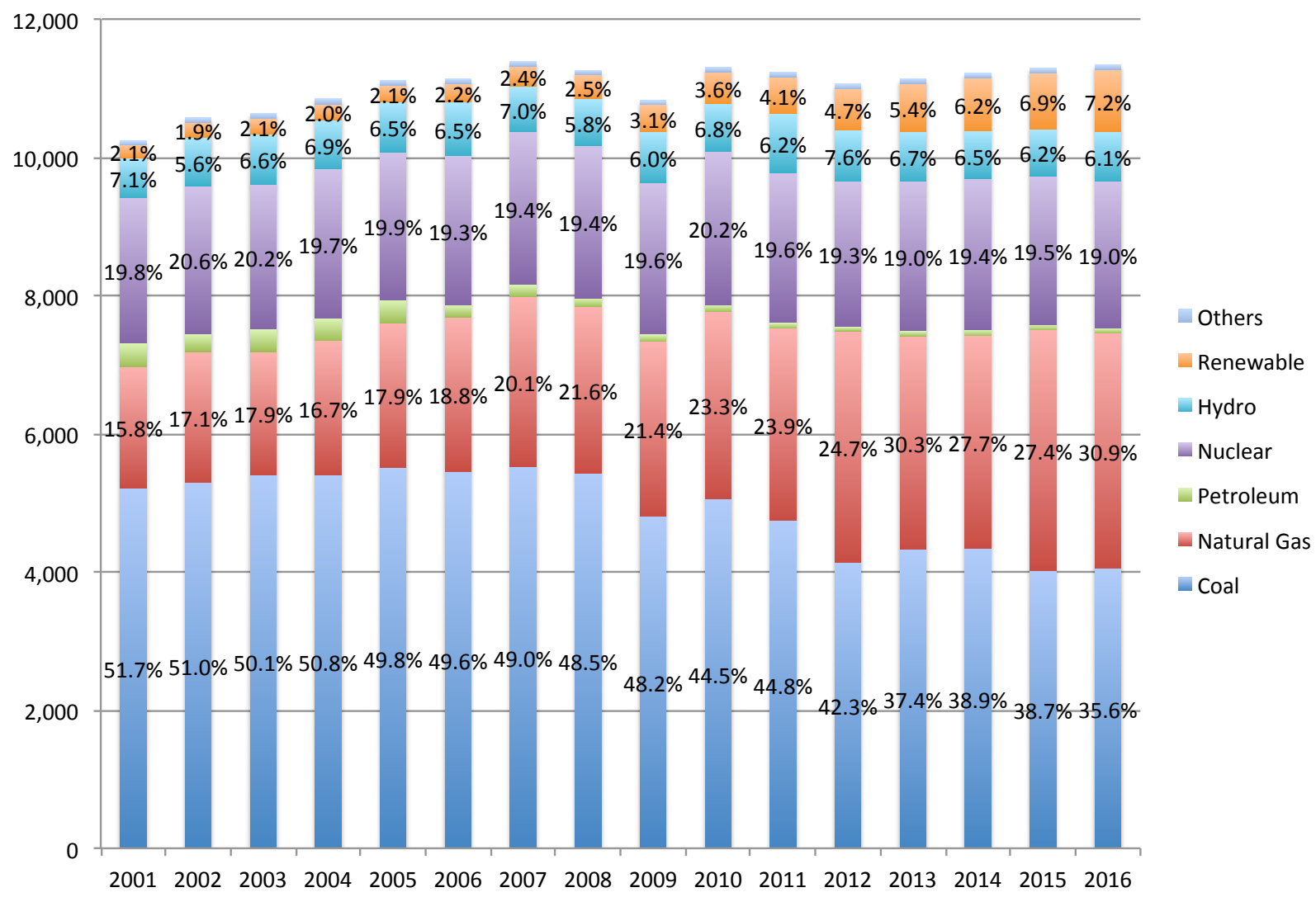

Note: Entries for 2015 and 2016 are forecast. "Renewable" refers to generations from nonhydro renewable sources. Labels show percentage share.

Source: U.S. EIA Short-term Energy Outlook.

Figure 1. U.S. electricity generation by fuel (in 1,000 MWh per day). 


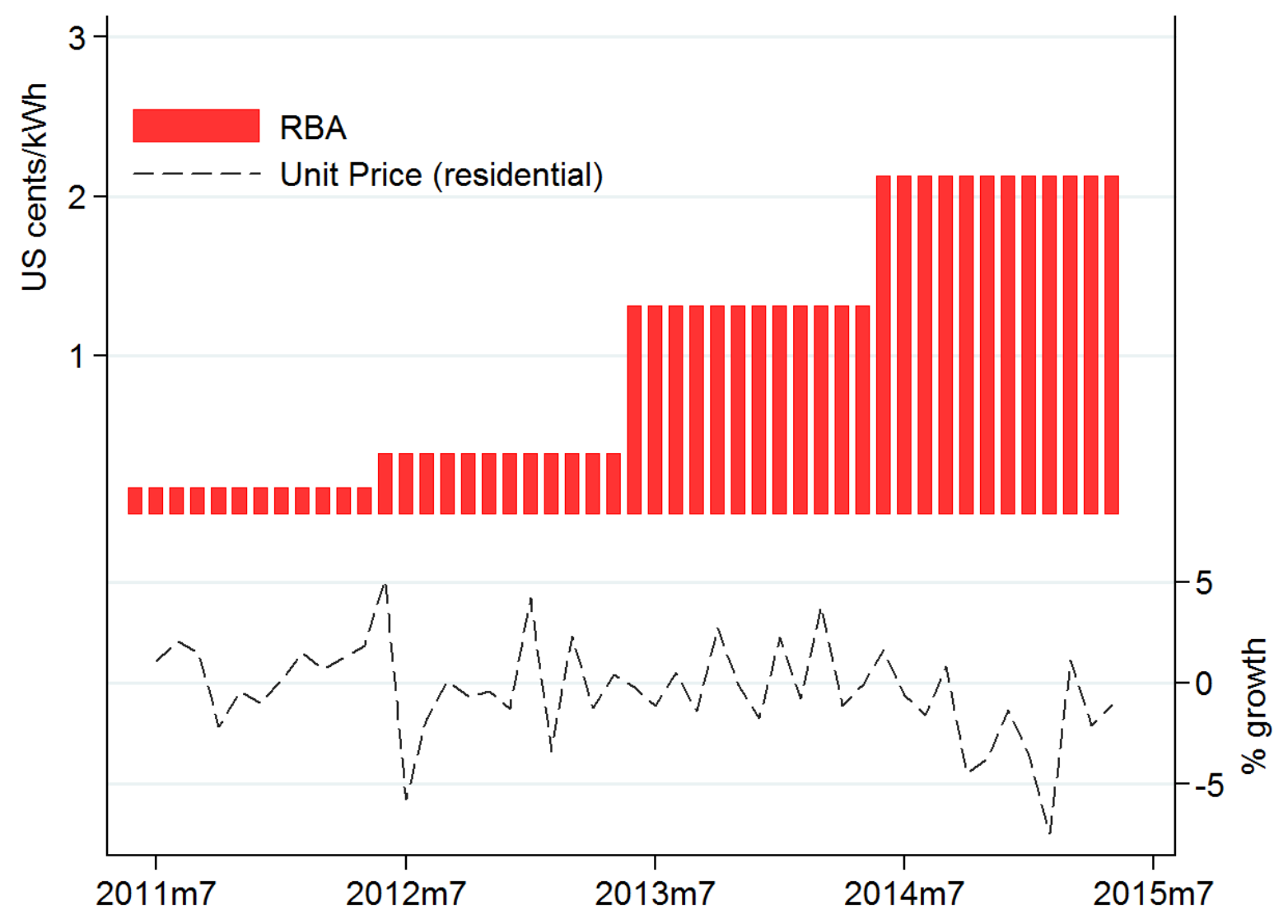

Note: The top panel represents the revenue decoupling adjustment under Revenue Balancing Account (RBA). The bottom panel displays the rate of change in the residential electricity rate. Compiled by the author based on Hawaiian Electric Companies "Effective Rates Summary for Hawaiian Electric, Maui Electric and Hawaii Electric Light Company" and U.S. EIA "average retail price of electricity."

Figure 2. Revenue decoupling adjustment and the rate of change in the residential electricity rate in Hawaii. 